\title{
Observatório
}

ISSN n² 2447-4266

Vol. 2, n 1, Janeiro-Abril. 2016

DOI: http://dx.doi.org/10.20873/uft.2447-4266.2016v2n1p92

\section{Memória Massacre \\ Carandiru: a história pública digital contra 0 esquecimento}

Memória Massacre Carandiru:

una historia digital pública

contra el olvido

Memória Massacre Carandiru: a digital public history against

oblivion

\section{Marta Gouveia de Oliveira Rovai ${ }^{1}$ Rafael Flores de Lima ${ }^{2,3}$}

\section{RESUMO}

Este artigo procura discutir o conceito de história pública digital e sua importância, por meio da apresentação do portal Memória Massacre Carandiru. Inicialmente, como pesquisadores do filme O Homem da Grade de Ferro (2003), que trata de narrativas orais e imagéticas de presos do complexo Carandiru, entramos em contato com as criadoras e organizadoras do site, cujo objetivo é reunir o maior número de documentos - iconográficos, judiciais, jornalísticos, fílmicos e orais - relativos ao massacre ocorrido no Complexo Penitenciário de São Paulo, no ano de 1992, e disponibilizá-los a uma audiência e debate público. O projeto pretende, ainda, criar um acervo de narrativas orais dos

\footnotetext{
${ }^{1}$ Professora Adjunta da Universidade Federal de Alfenas (UNIFAL/MG); Doutora em História Social pela Universidade de São Paulo (USP); Pós-doutoranda pela UFF. Coordena o Grupo de Pesquisa História do Brasil: memória, cultura e patrimônio E-mail: martarovai@usp.br.

${ }^{2}$ Graduado em Licenciatura em História pela Universidade Federal de Alfenas (UNIFAL/MG), membro do Grupo de Pesquisa História do Brasil: memória, cultura e patrimônio; pesquisador de Iniciação Científica pelo CNPq. E-mail: rfloreslima@gmail.com.

${ }^{3}$ Endereço de contato dos autores (por correio): Universidade Federal de Alfenas. Instituto de Ciências Humanas e Letras. Rua Gabriel Monteiro da Silva, 700, Centro - Alfenas/MG, CEP: 37130-000. Brasil.
} 


\section{Observatório}

ISSN n² 2447-4266

Vol. 2, n 1, Janeiro-Abril. 2016

DOI: http://dx.doi.org/10.20873/uft.2447-4266.2016v2n1p92

sujeitos envolvidos no evento, valorizando a memória esquecida/impedida sobre o trauma histórico, ainda hoje não devidamente enfrentado.

PALAVRAS-CHAVE: Massacre; Carandiru; história pública digital; memória.

\section{ABSTRACT}

This article discusses the concept of digital public history and its importance through the presentation of portal Memória Massacre Carandiru. Initially as film researchers O Homem da Grade de Ferro (2003), which deals with oral and imagistic narrative of prisoners Carandiru complex, we contacted the creators and organizers of the site, which aims to bring together the largest number of documents - iconographic, legal, journalistic, filmic and oral - for the massacre in the Penitentiary of São Paulo, in 1992, and make them available to an audience and public debate. The project also intends to create a collection of oral narratives of the subjects involved in the event, valuing the memory forgotten/prevented on historical trauma, still not properly addressed.

KEYWORDS: Massacre; Carandiru; digital public history; memory.

\section{RESUMEN}

En este artículo se discute el concepto de la historia pública digital y su importancia a través de la presentación del portal Memória Massacre Carandiru. Inicialmente como investigadores de la película O Homem da Grade de Ferro (2003 ), que trata de la narración oral y lleno de imágenes de prisioneros complejo de Carandiru, se estableció contacto con los creadores y organizadores del sitio, que tiene como objetivo reunir el mayor número de documentos - iconográfico, jurídica, periodística, cinematográfica y orales - de la matanza en la Penitenciaría de San Pablo, en 1992, y ponerlos a disposición de un público y el debate público. El proyecto también tiene la intención de crear una colección de relatos orales de los sujetos involucrados en el caso, la valoración de la memoria olvidada/impedido el trauma histórico, todavía no se aborda adecuadamente .

PALABRAS CLAVE: Matanza; Carandiru; historia digital pública; memória.

Recebido em: 11.02.2016. Aceito em: 13.03.2016. Publicado em: 30.04.2016. 


\section{Observatório}

ISSN n² 2447-4266

Vol. 2, n 1, Janeiro-Abril. 2016

DOI: http://dx.doi.org/10.20873/uft.2447-4266.2016v2n1p92

"Carandiru é coisa do passado". Antonio Ferreira Pinto Secretário de Segurança Pública de São Paulo

\section{Introdução}

O Brasil colhe hoje os frutos de um longo processo de transição democrática, que culminou - mas não se encerrou - com a entrega do relatório da Comissão Nacional da Verdade (CNV) à presidenta Dilma Rousseff, no final de 2014. Vive-se a chamada Justiça de Transição, que se caracteriza por ações políticas e sociais no sentido de lidar com a herança de violência e com os traumas coletivos advindos do regime autoritário brasileiro e colocar em debate o direito à memória, à verdade e à justiça, no enfrentamento doloroso e necessário do passado coletivo.

A importância de se relembrar o passado não significa "resgatá-lo" do esquecimento, porque a memória é processo sempre presentificado pelas experiências, angústias e expectativas da sociedade que procura compreender as permanências e continuidades de violações contra a dignidade humana e que pretende, a partir delas, modificar seu presente, translaborar as suas dores. Nesse sentido, é imprescindível tornar pública cada história, reivindicar a nomeação dos culpados, a responsabilização e as reparações, estabelecendo-se um confronto político, histórico e até mesmo jurídico entre os que executaram e foram coniventes e aqueles que combateram as violações dos direitos humanos. Isso significa dar acesso aos fatos e seus significados às gerações posteriores, que herdam e sofrem a disputa por memórias que não lhes pertencem diretamente como passado, mas que passam a fazer sentido em sua 


\section{Observatório}

ISSN n² 2447-4266

Vol. 2, n 1, Janeiro-Abril. 2016

DOI: http://dx.doi.org/10.20873/uft.2447-4266.2016v2n1p92

vivência no presente, na medida em que feridas permanecem abertas e barbaridades se repetem.

No caso deste artigo, interessa-nos apontar para a necessária memória sobre violações cometidas não apenas contra os presos políticos e opositores do regime ditatorial brasileiro (1964/84) - o que de certa forma se amplia com os depoimentos dados à CNV e também com inúmeros trabalhos acadêmicos e criação de acervos e memoriais - mas contra aqueles que continuam a ser violentados e silenciados ainda no regime democrático: os chamados "presos comuns", em especial aqueles que viveram e sobreviveram ao massacre no Sistema Penitenciário de São Paulo, conhecido como Carandiru, no ano de 1992.

Este artigo é resultado do processo de pesquisa ${ }^{4}$, que procurou compreender o universo prisional, por meio de narrativas orais de detentos no Complexo Prisional Carandiru, em São Paulo, antes de sua implosão em 2001. O filme, exibido em 2003, nasceu de uma iniciativa do diretor Paulo Sacramento, que ofereceu aos presos sete meses de treinamento com câmeras, para que eles mesmos pudessem construir um roteiro e registrar imagens e relatos sobre a vivência no cárcere, a partir de seu próprio olhar ${ }^{5}$.

O documentário funcionou como um suporte de memória daqueles homens contra a indiferença social e a postura de certa parcela da mídia, preocupada muito mais em estigmatizá-los do que problematizar a questão da

\footnotetext{
${ }^{4}$ Pesquisa de Iniciação Científica "Memórias e identidade do encarceramento: análise das narrativas orais no documentário O Prisioneiro da Grade de Ferro", desenvolvida na Universidade Federal de Alfenas (UNIFAL/MG), financiada pelo CNPq.

${ }^{5}$ Não foi nosso objetivo, aqui, tratar do documentário em si, mas indicar que foi dele que partimos e que ele é uma das possibilidades de ampliação de vozes dos encarcerados. Ativemonos à discussão em torno do acervo digital Memória Massacre Carandiru, do qual ele faz parte, acessível em http://www.massacrecarandiru.org.br/.
} 


\section{Observatório}

ISSN n² 2447-4266

Vol. 2, n 1, Janeiro-Abril. 2016

DOI: http://dx.doi.org/10.20873/uft.2447-4266.2016v2n1p92

estrutura carcerária como algo que envolve também quem está fora dela. As narrativas orais também implicaram as imagens, uma expansão da voz, na medida em que revelaram situações não ditas, silenciadas pela opressão prisional e pelo desinteresse coletivo em saber o que ocorre por trás dos muros dos presídios.

A exibição do filme, no entanto, não significou a necessária publicização e problematização sobre a condição histórica dos cárceres no Brasil. Desde a destruição dos prédios, pouco se tratou da complexidade de experiências de detentos e sobre a violação aos direitos humanos, efetuada pelo assassinato de 111 presos e pelo apagamento dessa memória. A pesquisa em torno das narrativas, por meio do filme, levou-nos a procurar outras possíveis formas de ampliar o debate em torno do significado de tal tragédia. Assim, mantivemos contato com os criadores do acervo digital Memória Massacre Carandiru, sob a iniciativa do Núcleo de Estudos sobre o Crime a Pena, da FGV Direito SP, em parceria com a Associação Nacional de Direitos Humanos, Pesquisa e Pósgraduação (Andeph), coordenados pelas pesquisadoras Marta Machado e Maíra Machado e com as quais nos predispusemos a colaborar.

Preocupado com o esquecimento social gerado pela própria mídia em relação aos acontecimentos de 1992, o que faz perdurar a cegueira relativa às condições das prisões no Brasil, este acervo virtual pretende manter vivas memórias que não se reduzem ao passado, mas lembram ao presente que as feridas ainda estão abertas e que a ampliação cada vez maior da comunicação pode contribuir não só para a divulgação mais ampla de informações sobre os acontecimentos de 1992, mas para ouvirmos as vozes daqueles que não puderam apresentar as suas versões, revelando uma estrutura prisional repleta de falhas e de estratégias de estigmatização e desumanização ainda 


\section{Observatório}

ISSN n² 2447-4266

Vol. 2, n 1, Janeiro-Abril. 2016

DOI: http://dx.doi.org/10.20873/uft.2447-4266.2016v2n1p92

persistentes. Tratamos, aqui, do conceito e relevância da chamada memória pública digital, sobre a qual procuramos nos deter por meio da apresentação do acervo virtual Memória Massacre Carandiru.

\section{O massacre do Carandiru: memórias traumáticas subterrâneas}

A chacina de pelo menos 111 presos, no Complexo do Carandiru, ocorreu em 02 de outubro de 1992. Uma briga entre os detentos, no pavilhão 9, serviu de pretexto para a invasão do presídio pela tropa de choque e o assassinato, indiscriminado, dos encarcerados. De imediato, as notícias estamparam as primeiras páginas de jornais e revistas e tomou conta dos noticiários. No entanto, não demorou muito para que cada vez mais o debate em torno do acontecimento se afastasse dos espaços públicos e caísse num esquecimento perigoso ao processo de democratização e cidadania. Em abril de 2000, a Comissão Interamericana de Direitos Humanos da Organização dos Estados Americanos condenou o Brasil pela inação relativa à responsabilização dos crimes cometidos pelo Estado, considerando-o "um massacre no qual o Estado violou os direitos à vida e à integridade pessoal e que, em suas sequelas, também foram violados os direitos ao devido processo e à proteção judicial" (artigos 4,5, 8 e 25$)^{6}$.

Diante de tamanha negligência e permanência de um sistema penal falido e injusto, é que o volume $V$ do relatório apresentado pela Comissão da Verdade, em dezembro de 2014, apontou não apenas para a necessidade de

\footnotetext{
${ }^{6}$ Somente no ano de 2013 é que teve início o processo de julgamento dos envolvidos, resultando na condenação de 77 policiais, que receberam penas entre 96 e 624 anos de prisão, mas que respondem por elas em liberdade.
} 


\section{Observotório}

ISSN n² 2447-4266

Vol. 2, nº 1, Janeiro-Abril. 2016

DOI: http://dx.doi.org/10.20873/uft.2447-4266.2016v2n1p92

relembrar o passado do regime autoritário - que ainda não passou - mas também para a permanência das violações cometidas nas prisões brasileiras:

A estrutura prisional brasileira expressa uma situação de profundo desrespeito aos direitos humanos. A superpopulação prisional - fruto, inclusive, do uso pouco disseminado de penas alternativas - e a ausência efetiva de políticas voltadas a reintegração social dos presos são fatores que induzem a população carcerária a falta de perspectiva. Os presídios são locais onde a violação múltipla desses direitos ocorre sistematicamente, já foi feito o questionamento desse quadro ate mesmo por órgãos internacionais. Essa situação também se verifica nas instituições destinadas ao acolhimento de crianças e adolescentes infratores.

(...)Nesse contexto, recomenda-se especial atenção a adoção de medidas que dignifiquem os presídios, promovendo-se 0 respeito aos direitos humanos e afastando-se a adoção de medidas - por exemplo, a privatização dessas estruturas - que acarretem ruptura com o princípio de que o poder punitivo e exclusivo do Estado e deve ser exercido nos marcos do Estado democrático de direito.(CNV, 2014, p.969)

Em torno da ideia de defesa dos direitos humanos também de presos que continuam a sofrer violência no sistema carcerário, sob o regime democrático, e da valorização de suas memórias, ignoradas pela indiferença social aos considerados criminosos, deve-se lembrar a importância da publicização de suas histórias, seja pela contribuição de filmes como Prisioneiro da Grade de Ferro $(2003)^{7}$, que trabalha com a oralidade de encarcerados e suas

\footnotetext{
${ }^{7}$ Existem hoje vários filmes que procuram expor a questão da violência prisional e da (in)justiça penal no Brasil, cabendo destaque; ao documentário Justiça - O Filme (2004), de Maria Augusta Ramos, que mostra um Tribunal de Justiça no Rio de Janeiro, acompanhando o cotidiano de alguns personagens; ao filme Juízo (2008) de Maria Augusta Ramos, aos documentários Entre e luz e a sombra (2009), de Luciana Burlamaqui, $A$ casa dos mortos (2009) de Débora Diniz, um olhar sobre a realidade dos manicômios judiciários; Leite e ferro (2010) de Claudia Priscilla, sobre a maternidade de presas, e o documentário Sem Pena, (2014), de Eugenio Puppo, sobre os processos judiciais e as prisões no Brasil.
} 


\section{Observatório}

ISSN n² 2447-4266

Vol. 2, n 1, Janeiro-Abril. 2016

DOI: http://dx.doi.org/10.20873/uft.2447-4266.2016v2n1p92

experiências, como pela criação recente do portal Memória Massacre do Carandiru, em 2015, que procura reunir documentos judiciais e jornalísticos sobre o acontecimento, assim como, por meio da história oral, ampliar os ouvidos diante dos testemunhos dos sujeitos envolvidos.

Só para lembrar, a primeira cena do O prisioneiro da Grade de Ferro, um dos filmes pioneiros a tratar sobre o problema carcerário no Brasil, já é significativa em relação à questão do esquecimento, pois mostra a demolição do Carandiru, cena introduzida posteriormente no filme: a destruição do prédio, em meio à fumaça, é apresentada no início e, logo depois, é mostrada em tempo invertido (da demolição para o prédio em pé), como a mostrar o próprio silenciamento de tantas histórias, uma tentativa de apagar as experiências vivenciadas ali e reduzi-las às ruínas. Em seu lugar foi erigido o Parque da Juventude, mas a inexistência arquitetônica do presídio não consegue dar conta de fazer desaparecer as histórias subterrâneas, ainda presentes nas memórias cotidianas dos que sobreviveram.

Como afirmou Michael Pollak (1989), as memórias subterrâneas nunca desaparecem, mesmo que sofram processos de opressão e sejam substituídas por tentativas de apagamento. São lembranças ressentidas, envergonhadas, do não dito e oprimido ${ }^{8}$. Porém, elas subsistem para emergir em momentos de crise e de confronto, prontas para apresentarem-se e posicionarem-se contra uma memória unívoca, homogênea e enquadrada. Assim são entendidas as narrativas dos presos: seus testemunhos lembraram, desde o início, da recepção irônica do carcereiro, humilhando e desumanizando, de imediato, aqueles que chegavam. Revelaram as condições das celas, muito sujas e abarrotadas de

\footnotetext{
${ }^{8}$ Poderíamos usar, também, a expressão de Paul Ricouer (2007) "memória impedida", aquela que é fruto da humilhação e que, proibida de se manifestar, não pode ser curada.
} 


\section{Observatório}

presos. Em meio a isso, a seleção de imagens, feita por eles, procurou mostrar também suas relações de amizade e as disputas por territórios dentro da prisão. Cabe destacar, ainda, as diversas formas de resistência, seja pela procura por diferentes religiões que dividiam os detentos em busca de salvação ou de diminuição de suas culpas, seja pela produção/tráfico de drogas/bebidas clandestinas ou de armas, usando de material encontrado dentro do próprio presídio.

Suas memórias não os reduzem à posição de vítimas nem de algozes, mas de pessoas, de resistentes e de sobreviventes de um conjunto de regras disciplinares, de ordenação de seus corpos e mentes, de desigualdade social e de poucas alternativas, de fato, de ressocialização.

Sem querer nos deter sobre o filme, interessa-nos apontar para o fato de que mais do que memórias, seus relatos são discursos, na tentativa de dialogar com quem está fora da prisão, procurando romper preconceitos e mostrar que a realidade carcerária é muito mais complexa do que o mundo dividido entre o bem e o mal. Suas narrativas são recursos para se pensar a própria história, explorando dimensões que extrapolam as acadêmicas, como é o caso da violência e a desigualdade social. São denúncias de uma sociedade desigual e perversa, e de uma noção de justiça que, muitas vezes, se confunde com a vingança.

Sobre essa cultura vingativa e injusta, Renato Janine Ribeiro já havia apontado para o papel que a violência histórica teve em nossa formação social e cultural, constitutivo, segundo ele, de dois traumas fundamentais e insuperáveis: 


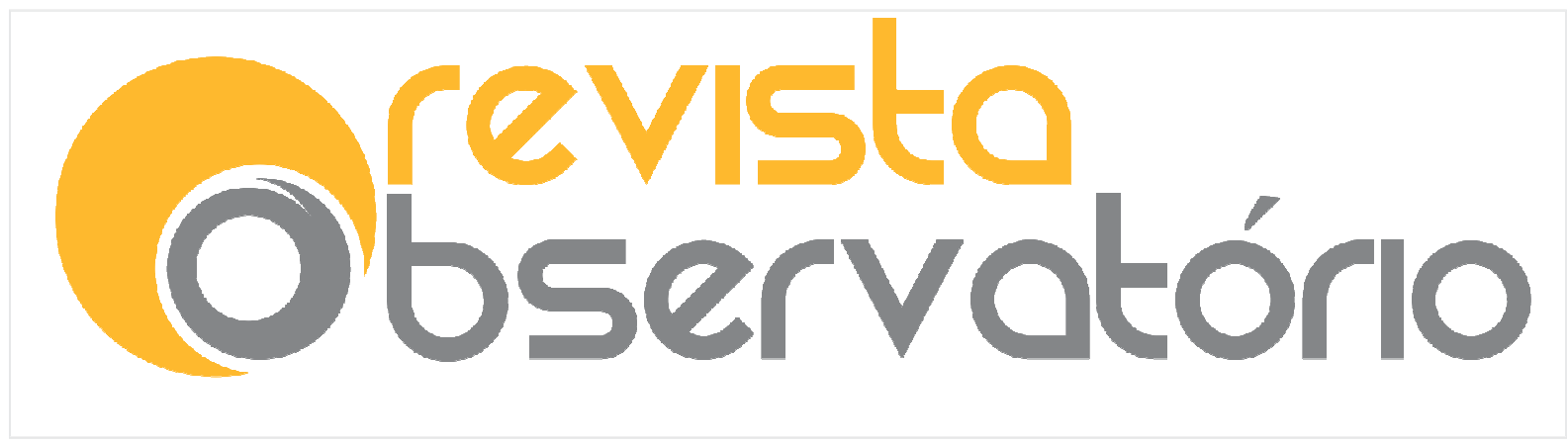

ISSN n² 2447-4266

Vol. 2, n 1, Janeiro-Abril. 2016

DOI: http://dx.doi.org/10.20873/uft.2447-4266.2016v2n1p92

O primeiro está associado ao impacto histórico de séculos de exploração colonial, forjada de modo violento, dos momentos iniciais à independência no início do século XIX. O segundo está vinculado à crueldade inerente à escravidão, que sustentou o processo de formação do Estado Nacional, no período imperial. Somos herdeiros, na perspectiva de Ribeiro, de duas experiências dolorosas, de sujeição à agressão, de ausência de senso coletivo, de absoluta falta de consideração com relação à maioria dos habitantes por parte das elites. Nossa formação social é resultado de um processo intensamente truculento, cujas consequências se fazem sentir até o presente, pois suas dores nunca foram inteiramente superadas. (RIBEIRO Apud GINZBURG, 2012, p.473)

Esta constatação histórica coloca em evidência a existência de traumas que a sociedade brasileira evita lembrar, evitando reencontrar a si mesma e enxergar-se não apenas como vítima, mas como parte das perpetrações efetivadas cotidiana e silenciosamente. Para Jaime Ginzburg (2012), a maior parte dos governos procuraram se ancorar nessa cultura autoritária para perpetuarem suas práticas de opressão, fortalecendo ainda ações de violações que continuaram a existir nos regimes democráticos. Como resposta ao enfrentamento da dor, muitas vezes optamos, como sociedade, pela trivialização da violência, a tal ponto em que o estranhamento e reflexão necessários sejam abolidos e que a exclusão, a condenação e o horror cometidos contra certos grupos sejam naturalizados e aceitos, confundindo-se silenciamento com noções banalizadas de justiça e de ressentimento social:

A conservação de valores por parte das elites, estrategicamente articulada com uma política educacional e cultural dedicada à preservação da desigualdade de condições de acesso ao conhecimento, tem permitido que, mesmo em períodos considerados democráticos, várias das grandes instituições legislativas, executivas, educacionais, responsáveis pela saúde e pelos problemas sociais se comportem de modo a manter a desigualdade e a hierarquia, cultivando ideologias autoritárias. 


\section{Observatório}

ISSN n² 2447-4266

Vol. 2, n 1, Janeiro-Abril. 2016

DOI: http://dx.doi.org/10.20873/uft.2447-4266.2016v2n1p92

Para que essa estratégia funcione, a degradação da memória social é um elemento decisivo. A tensão entre linguagem e silêncio, entre o que falar e o que calar, é uma das suas marcas. O cultivo do fascínio pelo horror, e a contemplação sem estranheza da violência sobre o outro, também interessam. (GINZBURG, 2012, p.476)

Assim tem sido a discussão, no tempo presente, sobre a permanência das torturas e assassinatos nas prisões brasileiras. Todo o amplo e complexo processo de violência e exclusão social - e a punição da pobreza - parece ter se reduzido à redução da maioridade penal, assim como à aceitação, por grande parte do público, dos linchamentos e extermínio de pessoas consideradas o mal social. Nossa história de exclusão, marcada pela prática da escravidão e do genocídio indígena ao longo de nossa história, além do longo período ditatorial, pouco é enfrentada, alimentando a ideia de que determinadas atrocidades sejam "aceitáveis". Nesse sentido, concordamos com Ginzburg e Ribeiro, para quem construímos uma história baseada no autoritarismo e na indiferença: vivemos o excesso da violência, da dor e da injustiça pelo ataque aos menos favorecidos, os massacres étnicos e pela repressão aos movimentos populares promovidos pelos governos autoritários, em diferentes momentos. $\mathrm{O}$ Brasil foi fundado sobre a violência extrema, estruturante, que ajudou a moldar as relações sociais e políticas, assim como o padrão de dominação que permanece no país, condenando pobres, em sua maioria, a pagar - de forma vingativa - pelos problemas que são sociais. Os presídios são extensões dessa brutalidade histórica.

Um tempo de escuta e olhar atentos: um esclarecimento necessário sobre história pública digital no debate e divulgação de memórias 


\section{Observatório}

ISSN n $2447-4266$

Vol. 2, no 1, Janeiro-Abril. 2016

DOI: http://dx.doi.org/10.20873/uft.2447-4266.2016v2n1p92

O filósofo espanhol Josep Esquirol (2008) afirmou que vivemos hoje num "mundo de indiferentes", submersos na corrente do excesso informações e de hiperconsumo, perdendo gradativamente a sensibilidade para ouvir e ver as pessoas e suas experiências. Assumimos uma postura de distanciamento em relação ao "outro", na medida em que isso facilita nossa capacidade de transformá-los em "monstros", desumanizando-os e tirando de nós a responsabilidade pelo compartilhamento de sua condição de opressão. Passamos a entender a violência como uma relação unilateral ou binária, dividindo o mundo entre "maus e bons", "vítimas e perpetradores".

Tornamo-nos indiferentes e isso não se deve à ausência de informações, mas ao seu oposto: um excesso de cenas e histórias padronizadas que banalizam as barbaridades e fazem-nas pertencerem a certa normalidade e aceitação cotidiana, principalmente quando ela é aplicada contra aqueles que, todos os dias, são apontados pela mídia como responsáveis pelo nosso sofrimento e insegurança. Sem reflexão sobre o passado histórico e, consequentemente, sem entendê-lo como extensão no presente, tratamos a violação dos direitos humanos nos presídios como certa normalidade e como solução ingênua para nossa própria insegurança.

Por outro lado, o processo de transição democrática também produz outros movimentos sociais e políticos que procuram romper com a apatia social e com os preconceitos: discussões sobre a defesa dos direitos humanos se ampliam, levando à organização de grupos em defesa de minorias e à criação de centros e acervos que promovam a memória em tempos de desumanização e esquecimento. Aqui cabe a referência ao objeto deste artigo, a iniciativa de criação de um portal digital que promova a memória do massacre de 111 


\section{Observotório}

presos, no Carandiru, em 1992, procurando ampliar a discussão social em torno de seu esquecimento e as sequelas disso em relação aos direitos humanos.

A procura pela preservação de memórias é fruto do longo processo de redemocratização no Brasil. A partir dos anos 1970, começou a se desenvolver a criação de centros documentais em universidades, voltados à memória e pesquisa, em meio ao processo de movimentos sociais - feministas, negros, indígenas, comunidades eclesiais de base - que pressionavam o Estado pelo respeito à alteridade e à dignidade humana. Com diferenciados nomes acervos, centros, arquivos ou memoriais - esses órgãos se preocuparam em reunir, catalogar, organizar e disponibilizar informações de qualidade, necessárias à consciência histórica e à memória coletiva. Dentre eles, destaca-se o Centro de Pesquisa e Documentação (CPDOC), no Rio de Janeiro, criado em 1975, ou ainda o Centro de Documentação e Informação Científica (CEDIC), da Pontifícia Universidade Católica de São Paulo, em 1980. Acervos como esse inovavam quanto ao papel dos espaços de pesquisa, adotando-se não apenas função acadêmica ou de reserva de documentos (muitas vezes restritos e nunca utilizados), mas também uma política cultural de acervos preocupada em publicizar informações e memórias até então relegadas pelo regime autoritário.

Esta preocupação em se reunir documentos sobre a história brasileira se ampliou na medida em que acervos de fontes orais também se constituíram, buscando em narrativas particulares aspectos da memória coletiva. Essas tentativas de valorização das fontes orais foram acompanhadas do refinamento da metodologia e dos usos tecnológicos para o registro, conservação e disponibilização da oralidade. Sem querer entrar em detalhes sobre os diferentes centros criados, interessa-nos apontar para a criação de arquivos na contemporaneidade, no contexto da informação rápida e da tecnologia que se 


\section{Observotório}

ISSN n² 2447-4266

Vol. 2, n 1, Janeiro-Abril. 2016

DOI: http://dx.doi.org/10.20873/uft.2447-4266.2016v2n1p92

desenvolve diferente dos arquivos tradicionais, contexto em que se insere o portal Memória Massacre Carandiru.

A procura por caminhos que tornem as fontes acessíveis a um público mais amplo e com maior rapidez promoveu a ideia de História Pública, uma temática que tem tomado conta dos debates acadêmicos desde os anos 1960, na Europa, e que no Brasil, apesar de ser discussão mais recente, ganha mais espaço entre os acadêmicos e comunidades ${ }^{9}$. Aqui, cada vez mais eventos e obras têm sido organizados para se pensar este novo conceito, que envolve não apenas os profissionais da História, mas a interdisciplinaridade dos mais diferenciados especialistas ${ }^{10}$. Busca-se pensar a história pública como possibilidade de difundir o conhecimento histórico - de maneira responsável, problematizada e integrada - para amplas audiências e para diferenciados sujeitos que também possam participar de sua elaboração.

Torná-la "popular" não significa abandonar os parâmetros do fazer histórico nem tão pouco banalizá-la pelo excesso de informações, ou confundir a história pública com o popularesco, o anedótico ou a curiosidade. Representa estimular diálogos e reflexões públicas. Significa usar as diferentes mídias - em especial, hoje, a internet - a fim de colocar na arena pública as demandas coletivas, democratizando os saberes. Isso implica em entender a ideia de publicização não apenas como organização, preservação e divulgação de

\footnotetext{
${ }^{9}$ O debate sobre História Pública teve início na Inglaterra, nos anos 1970, e ganhou espaço no Canadá, Austrália, Itália, África do Sul e Estados Unidos. Na Europa, emergiu como prática do uso público da história com fins político-ideológicos, influenciados pela ideia da justiça social e pelos movimentos ligados às feministas e aos negros. Nos Estados Unidos, os historiadores públicos preocupam-se mais com os meios de acesso e divulgação de uma história para comunidades mais amplas.

${ }^{10}$ No Brasil, formou-se a Rede Brasileira de História Pública (RBHP), desde 2012. Desde então, o Simpósio Internacional de História Pública está em sua terceira versão, e a obra Introdução à História Pública (ALMEIDA; ROVAI, 2011) foi organizada no intuito de estimular o debate.
} 


\section{Observotório}

ISSN n² 2447-4266

Vol. 2, n 1, Janeiro-Abril. 2016

DOI: http://dx.doi.org/10.20873/uft.2447-4266.2016v2n1p92

acervos, mas disciplinaridade, debate e integração de recursos diversos para se pensar as relações entre passado e presente. Enfim, como tornar o passado útil para o tempo presente:

A história pública é um conceito escorregadio por abrigar múltiplas tendências profissionais e acadêmicas, e por isso exige responsabilidade e compromisso acadêmico e social. A prática da história pública como "apresentação popular do passado para uma gama de audiências" se relaciona com a forma como adquirimos nosso senso do passado, colaborando para nosso posicionamento sobre o presente e o futuro frente a questões que dizem respeito a problemas sociais, tradições culturais, hábitos, demandas de gênero e de classe, e a demanda por políticas públicas. (ALMEIDA; ROVAl, 2005, p.5)

Para que se possa cada vez mais ampliar a atuação da história pública, Gerald Zahavi (2011) sugere uma série de práticas fundamentais dentro e fora da academia: organização de acervos históricos e arquivísticos com as mais diferenciadas mídias; estudos museológicos; trabalhos com ficção (teatro e cinema) arte dramática; estudos de locais comemorativos e memória; trabalhos com rádio e documentários; usos da história oral; história digital/museus virtuais; trabalho com políticas públicas. O campo é amplo e ainda demanda muitos estudos e comprometimento de pessoas envolvidas com a comunidade acadêmica interessada em dialogar com a sociedade civil e entender suas necessidades e riquezas de experiências histórico-culturais.

Em busca da conservação e da ampliação do acesso a esse tipo de material, ganham importância os arquivos e centros de documentação de fontes orais como o Centro de Documentação e Informação Científica (CEDIC) ligado à Pontifícia Universidade Católica de São Paulo $(P U C / S P)^{11}$. Segundo

\footnotetext{
${ }^{11}$ O centro preserva um grande acervo de relatos orais, acompanhados da transcrição, além de roteiros, áudios, cadernos de campo e documentos pessoais, doados por pesquisadores ou
} 


\section{Observatório}

ISSN n² 2447-4266

Vol. 2, n 1, Janeiro-Abril. 2016

DOI: http://dx.doi.org/10.20873/uft.2447-4266.2016v2n1p92

Fernandes (2011), o espaço oferece aos pesquisadores um acervo de testemunhos relacionados com movimentos sociais, cultura urbana e rural, educação, utilizado por diferentes áreas do conhecimento. Mais amplo do que isso, a criação de arquivos digitais, como Memória Massacre Carandiru, tornamse fundamentais para a construção de uma consciência histórica em torno de experiências narradas por aqueles que as vivenciaram e que, muitas vezes, não tiveram a oportunidade de compartilhá-las, ultrapassando o espaço acadêmico.

Segundo Serge Noiret, o desenvolvimento do mundo digital ampliou a ideia de público e modificou as relações entre passado e presente, trazendo de forma cada vez mais intensa a presença de lembrança e disponibilizando-a a um número maior de pessoas numa velocidade mais rápida o que antes poderia permanecer restrito ao debate intelectual. Isso deu origem ao conceito de história pública digital ${ }^{12}$, o que não alterou a seriedade e o compromisso com a história, nem fez desaparecer as tradicionais formas de se constituir arquivos, mas colabora para que fontes e documentos sejam acessíveis a um grande público e para que a participação no debate provocado por disputas políticas em torno da memória seja estendida, saindo dos espaços acadêmicos e trazendo a história para o espaço virtual, mais amplo, em forma do que Noiret chamou de "ego-narrações" em rede (2015, p.34).

O desenvolvimento da tecnologia digital e, em especial da internet,

produzidos por seus membros. A internet é um recurso utilizado pelo CEDIC a fim de ampliar o acesso aos relatos, além da criação de comunidades virtuais que possam interagir por meio de debates sobre as experiências, assim como sobre os cuidados éticos no uso desse tipo de fonte. ${ }^{12}$ A "história digital" (digital history), que disciplina a relação entre as tecnologias de rede e a disciplina história, por meio das plataformas sociais e das mídias sociais, contribuiu, assim, para abrir a um público maior, e também de forma participativa, à "alta cultura" e, nos melhores casos, com a mediação de historiadores profissionais, os historiadores públicos (NOIRET, 2015, p.34). 


\section{Observatório}

tiraram o controle exclusivo do conhecimento histórico pela comunidade acadêmica, mesmo que ela tenha a iniciativa. $O$ passado pode ser divulgado e compartilhado em rede, permitindo o acesso de forma mais facilitada, assim como a contribuição de diferentes segmentos na construção de acervos:

O recurso a uma espécie de saber comunitário, à participação pública na rede, que vem sendo comumente chamada crowdsourcing, sob várias formas e com diversos tipos de conteúdos, trabalho colaborativo e saberes, permitiu a gestão integrada dos conteúdos digitais por parte de quem tenha a possibilidade e o conhecimento para assim proceder. (...) a web deve ser compreendida como história "viva" e "pública", praticada de forma interativa por todos, e não mais limitada à atividade dos historiadores acadêmicos, que registram digitalmente, com frequência em formato fechado, as próprias publicações tradicionais. (NOIRET, 2015, p.35)

Para garantir o devido distanciamento no confronto com o passado, reunir e gerenciar diferentes documentos, selecionar, mediar, conectar públicos diversos, colocar à disposição os conhecimentos sobre diferentes acontecimentos que afetam o presente, por meio do potencial das tecnologias digitais, uma geração de novos pesquisadores, que Noiret chama de "historiadores públicos digitais" (digital public historians), tornam-se os intermediários, profissionais necessários para promover a democratização em torno dos novos arquivos "inventados" e trazidos para a rede devido à colaboração também da comunidade não acadêmica. A história pública digital produz novas formas de se ver, ouvir e sentir as experiências humanas.

\section{O acervo digital Memórias Massacre Carandiru e a publicização necessária}

Não cabe somente a especialistas a escolha dos lugares de memória ou do que deve ser lembrado, mas é na interconexão com os interesses das 


\section{Observatório}

ISSN n² 2447-4266

Vol. 2, n 1, Janeiro-Abril. 2016

DOI: http://dx.doi.org/10.20873/uft.2447-4266.2016v2n1p92

comunidades, na atualidade, que se deve direcionar a criação desses acervos virtuais. No caso deste artigo, a criação do acervo digital relativo à memória do massacre acontecido no Carandiru corresponde à demanda social contra o silenciamento da violência sofrida e pela exposição dos problemas relativos aos conceitos de justiça, crime e punição no Brasil. Aqui, trata-se dos "usos públicos" de tecnologias, de histórias e de memórias íntimas traumatizadas, que precisam se tornar útil contra um presentismo que tudo reduz, simplifica ou apaga, sem fomentar qualquer forma de crítica.

O portal procura reunir todo tipo de documento que colabore para o entendimento e o significado não apenas da barbaridade cometida contra presos em 1992, mas sobre o processo de violência histórica, física e simbólica, perpetrada nas camadas mais pobres do país, condenadas muitas vezes por sua condição econômica e social. Não se trata de defender os presos, ou de omitir os crimes cometidos por eles, mas colaborar para a ponderação reflexiva em torno de uma realidade muito mais complexa do que parece. Permite uma leitura interdisciplinar, chamando para o debate a Comunicação, a História, o Direito e a Educação.

Trata-se de pensar num público em sua forma mais extensa, procurando atingir uma rede de pessoas das mais diferentes origens e interesses, entendendo que pela internet passam milhões de usuários e que a reunião de fontes diferenciadas possa servir não somente a pesquisadores, mas àqueles preocupados com a temática da violência e da segurança, fornecendo uma discussão qualitativa, baseada em rica documentação. Mais do que isso, coloca-se em questão uma disputa por memórias, selecionando e revelando lembranças de grupos excluídos contra uma "memória/ou 


\section{Observatório}

ISSN n² 2447-4266

Vol. 2, n 1, Janeiro-Abril. 2016

DOI: http://dx.doi.org/10.20873/uft.2447-4266.2016v2n1p92

esquecimento oficial" do que teria significado o assassinato dos presos no Carandiru ou que sejam os presídios, no Brasil. Sobre a função dos arquivos, Maria Paula N. Araújo e Myrian S. Santos afirmam:

A construção de arquivos, notação de dados, organização de eventos e celebrações são atividades da memória que cumprem papéis sociais fundamentais na sociedade em que vivemos. No que diz respeito à formação e preservação de arquivos relacionados a períodos de dominação e violência, em que direitos humanos são desrespeitados, há sempre uma luta política importante sendo travada a cada momento. (...) Os arquivos, artefatos e relatos do passado têm sido utilizados como provas de um passado que foi deliberadamente esquecido pelas versões oficiais da história. (ARAÚJO; SANTOS, 2007, p.100)

Ali pode ser encontrada a agenda de inúmeros encontros organizados pelos coordenadores do projeto, como o Seminário Internacional de Pesquisa em Prisão, ocorrido em outubro de 2015. Constam também as mais diversas manifestações públicas, relembrando os mortos e colocando em questão as condições carcerárias, como também notícias de audiências públicas, apontando problemas e avanços na política carcerária brasileira.

O acervo reúne, também, um banco de dados com documentos relativos aos processos administrativos e judiciais, laudos e mais de 200 depoimentos, recortes de notícias (principalmente dos jornais Folha e Estado de São Paulo), processos internacionais, as sentenças proferidas, produções artísticas e culturais, artigos acadêmicos e fotografias sobre o Carandiru, todos coletados durante a pesquisa Carandiru (não) é coisa do passado, realizado pelo Núcleo. Esse arquivo digital continua sendo alimentado pela chamada aberta ao público, que pode opinar e contribuir com qualquer tipo de material.

Para além do aspecto jurídico, um dos itens mais importantes do 


\section{Observatório}

acervo digital é o conjunto de documentários com narrativas orais de expresos, seus familiares e de ex-funcionários, como Memórias de Sangue, produzido em 2009, 19 anos do Massacre, de 2011, e Depois das Grades e Sem Pena, gravados em 2014. Todos eles partem dos relatos orais de sobreviventes do massacre - como fez de forma inaugural O Prisioneiro da Grade de Ferro (2003), ou de experiências de pessoas que passaram pelo sistema carcerário, abrindo espaço para que os sujeitos possam se dar a conhecer por uma sociedade que ignora suas histórias. Os ex-presos também têm sua voz registrada pelo site, por meio da criação - ainda incipiente - de um banco de relatos orais, como o de Sidney Francisco Salles, que sobreviveu à tragédia.

Os documentários conseguem reunir uma série de testemunhos significativos sobre o processo de desumanização que o sistema penitenciário brasileiro consegue produzir, aproximando-se muito de projetos com história oral, na medida em que não se reduzem a entrevistas, mas preocupam-se, politicamente, em dar visibilidade e escuta a memórias negligenciadas e servem como meio de produção de discursos, de divulgação, de reflexão e de devolução a comunidades de destino formadas pelas pessoas encarceradas, muitas vezes vistas como "lixo humano". A memória individual de cada uma delas, expressa no portal digital, para lembrar Maurice Halbwachs $(2006)^{13}$, demonstra a complexidade das relações sociais e da memória coletiva nas quais estão inseridas.

Assim, o que parece pequeno, restrito, esquecido, "problema de outros", relegado ao passado e a um espaço específico, é problematizado pelo site na medida em que cruza dados, apresenta reflexões sobre nosso passado-

\footnotetext{
13 Halbwachs afirmou que "não lembramos sozinhos", pois as recordações são frutos de processos coletivos de interações sociais. As narrativas se dão pela linguagem, criação coletiva.
} 


\section{Observatório}

ISSN n² 2447-4266

Vol. 2, n 1, Janeiro-Abril. 2016

DOI: http://dx.doi.org/10.20873/uft.2447-4266.2016v2n1p92

presente histórico e busca debater alternativas. O próprio documentário Um Mundo sem Prisões apresenta a concepção de justiça restaurativa, pelo caminho da educação e recuperação de indivíduos. A história pública digital assume, nesse sentido, uma forma de transformar o que é aparentemente distante em algo que interesse ao público e que o envolva de alguma forma, sensibilizando-o para a realidade que é social, não "de alguns". Como afirmou Stephen Robertson (Apud Noiret, 2015), pensa-se em tornar aquilo que é local em um problema global, na medida em que a criação de novos espaços narrativos e interpretativos possa ser conhecida e provocar a reflexão sobre acontecimentos semelhantes, em outros lugares e comunidades ou possibilidades que atingem qualquer um.

A criação do site Memória Massacre do Carandiru é importante passo no sentido de organizar um acervo - notícias, fotografias, depoimentos judiciais, reportagens e testemunhos orais - disponibilizando-o para consulta, divulgando-o a um público amplo (os não acadêmicos, mas portadores de inúmeros outros saberes e visões de mundo) para que se tome conhecimento e se reconheça a necessidade da lembrança traumática, apagada de forma tão brutal quanto o massacre dos 111 presos. Para isso, elabora procedimentos de trabalho dos mais diversos para que se organize e apresente esses documentos na forma de denúncia social e testemunho.

\section{Considerações finais}

A criação de arquivos digitais, como Memória Massacre Carandiru, colabora para ampliar a concepção de história no tempo presente, ou seja, como a "história aberta" definida por Walter (1987). Não serve apenas para 


\section{Observatório}

garantir o acesso, a organização e a conservação de documentos dos mais diferentes tipos, mas apresenta-se como função social, na luta contra o esquecimento de um passado que não passou. A história pública digital pode exercer a função de informar, de estimular a pesquisa e ampliar a capacidade de audiência e debate, especialmente ao abrir espaço político para os testemunhos de tragédias humanas arbitrariamente ignoradas, mas não apagadas porque insistem em existir nas memórias de seus protagonistas.

Ao disponibilizar os documentos em suas diferentes tipologias, ao inserir relatos de experiências para além das fontes escritas e convidar o público a contribuir, o portal ajuda a compor várias narrativas sobre o que foi o massacre acontecido no Carandiru em 1992 e o que tem sido a justiça carcerária, no Brasil, até o momento. Dá visibilidade aos sujeitos e comunidades ignorados, pondera, expõe feridas, falhas e apresenta possibilidades de solução; convida à reflexão sobre nossa cultura autoritária e violenta, como nos lembraram Jaime Ginzburg e Renato Janine Ribeiro (2012). Mostra, também, às novas gerações, o absurdo e desnecessário uso da humilhação e do extermínio de seres humanos para combater problemas mais complexos e processuais.

A opção pelo uso da tecnologia em formato digital é também um posicionamento político, de comprometimento por parte de intelectuais preocupados em garantir o acesso e contribuição de qualquer pessoa disposta ao diálogo, ao entendimento das relações entre passado e presente, além de fomentar a discussão em torno de políticas públicas, uma das principais funções da história pública.

Comprometer-se em relembrar as atrocidades sofridas no passado e 


\section{Observatório}

ISSN n² 2447-4266

Vol. 2, n 1, Janeiro-Abril. 2016

DOI: http://dx.doi.org/10.20873/uft.2447-4266.2016v2n1p92

que continuam a ecoar, implica em não desviar olhar, ouvidos e alma do presente, abrindo espaço para a sensibilidade política na pesquisa e na reflexão acadêmica. É olhar em espelho; assumir responsabilidade com o conhecimento e posicionar-se diante da omissão e da permanência da violência contra grupos que não podem falar por si, independente de suas culpas e erros. É entender que os traumas de um grupo podem ser responsabilidade de toda uma cultura e sociedade, não apenas em relação ao seu passado, mas também à propagação de ações que comprometam o seu futuro. Nesse sentido, é significativa a afirmação de Araújo e Santos, ao se referirem a arquivos comprometidos com contextos autoritários e violentos: "O papel (...) não é o de explicar o que não pode ser explicado, mas manter viva a memória do que não pode se repetir." (ARAÚJO, SANTOS, 2007, p. 104)

O projeto Memória Massacre do Carandiru, em formato digital e virtual, faz convergir o conhecimento, a política, a utilidade e o senso de justiça, num necessário trabalho de perlaboração da memória fraturada dos detentos que sobreviveram ao assassinato e dos familiares dos mortos que, como eles, acabaram sendo condenados e punidos. $E$ também daqueles que continuam a sobreviver sob o regime carcerário brasileiro. O trabalho contínuo do acervo, em reunir toda a documentação possível sobre o acontecido, e que apenas está começando, procura dar contexto e nexo aos fragmentos do passado, aglutinando pessoas em torno de eventos e significados, produzindo a memória coletiva e o posicionamento político em torno de questões como justiça, criminalidade e cidadania de pessoas encarceradas e não encarceradas.

A história pública digital, aqui exemplificada, permite um novo olhar sobre nosso passado histórico, reconhecendo e assumindo nossa 


\section{Observotório}

ISSN n² 2447-4266

Vol. 2, nº 1, Janeiro-Abril. 2016

DOI: http://dx.doi.org/10.20873/uft.2447-4266.2016v2n1p92

responsabilidade coletiva sobre as práticas violentas que aconteceram e que se perpetuam devido ao desconhecimento ou à indiferença com relação a ele. Ter acesso ao debate, dispor-se a conhecer as experiências traumáticas pode promover também o possível trabalho terapêutico coletivo para que se possa restaurar o princípio da justiça e da transformação histórica, entendendo que as prisões não estão separadas, mas são parte das noções e práticas de (in)justiça e autoritarismo que ainda permanecem na sociedade brasileira. Isso significa ir além da constatação de provas históricas sobre o massacre ou da busca de culpados e inocentes, vítimas e perpetradores. É encarar a disputa histórica entre silêncios e memórias da qual falou Elizabeth Jelin:

Las borraduras y olvidos pueden también ser producto de una voluntad o política de olvido y silencio por parte de actores que elaboran estrategias para ocultar y destruir pruebas y rastros, impidiendo así recuperaciones de memorias en el futuro - recordemos la célebre frase de Himmler en el juicio de Nuremberg, cuando declaro que la "solución final" fue una "página gloriosa de nuestra historia, que no ha sido jamás escrita, y que jamás lo será". En casos así, hay un acto político voluntario de destrucción de pruebas y huellas, con el fin de promover olvidos selectivos a partir de la eliminación de pruebas documentales. Sin embargo, los recuerdos y memorias de protagonistas y testigos no pueden ser manipulados de la misma manera (excepto a través de su exterminio físico). ${ }^{14}$ (JELIN, 2001, p. 11)

\footnotetext{
${ }^{14 “}$ Rasuras e esquecimento também podem ser o resultado de uma vontade ou política de esquecimento e silêncio da parte dos atores que desenvolvem estratégias para se esconder e destruir provas e vestígios, impedindo a recuperação de memórias no futuro - lembre-se a famosa frase de Himmler no julgamento Nuremberg, quando declarou que a 'solução final' era uma 'página gloriosa na nossa história, que nunca foi escrito e nunca será.' Em tais casos, há um ato político voluntário de destruição de provas e impressões, a fim de promover o esquecimento selectivo da eliminação de provas documentais. No entanto, as recordações e memórias de protagonistas e testemunhas não podem ser manipulados da mesma maneira (exceto através de seu extermínio físico)".
} 


\section{Observatório}

ISSN n² 2447-4266

Vol. 2, n 1, Janeiro-Abril. 2016

DOI: http://dx.doi.org/10.20873/uft.2447-4266.2016v2n1p92

Podemos assistir, continuamente, a um processo paradoxal em que a amnésia e a apatia se mantêm diante do excesso de informações consideradas obsoletas e líquidas, como lembrou Zygmunt Bauman (2005). Ao mesmo tempo, no entanto, ações como a apontada neste artigo demonstram um esforço grandioso, por parte de intelectuais e dos movimentos civis, para que a memória relativa às humilhações e às violações da alteridade e dignidade humana, respondam ao esquecimento forçado e massificado, que rompe com vínculos sociais e banaliza a (in)existência humana. As memórias excedem a qualquer forma de controle, porque não podem ser apagadas completamente por atos arbitrários; resistem na vivência e nos sentidos. Precisam de espaços e brechas para virem à tona. Os acervos - no caso aqui, os digitais - tornam-se necessários "lugares de memória", para usar a expressão de Pierre Nora (1992), na ausência forçada de "memórias de lugares e acontecimentos".

A criação de um site voltado à memória sobre o massacre de 111 presos no Carandiru não diz respeito somente aos mortos ali deixados, mas aos problemas que estão dentro e fora dos muros das prisões brasileiras, incomodando uma superficial crença no isolamento de humanos para gerar uma ingênua e impossível "socialização" de detentos pelos caminhos da violação de seus direitos. Não se trata de produzir um excesso de material jornalístico, oral, fotográfico e fílmico, mantendo os efeitos perversos de banalização e estagnação, mas produzir a necessária sensibilização pela criação de fóruns de pesquisa e reflexão pública em torno da memória. Este é o papel que acreditamos exercer o portal Memória Massacre Carandiru.

\section{Referências bibliográficas}




\section{Observatório}

ALMEIDA, Juniele R.; ROVAI, Marta G. O. Introdução à História Pública. São Paulo: Letra e Voz, 2011.

ARAÚJO, Maria P.; SANTOS, Myrian S. História, memória e esquecimento: Implicações políticas. Revista Crítica de Ciências Sociais, n.79, Dezembro/2007, p. 95-111.

BAUMAN, Zygmunt. Identidade: entrevista a Benedetto Vecchi. Rio de Janeiro: Zahar, 2005.

BENJAMIN, Walter. Obras escolhidas. Magia e técnica, arte e política. Ensaios sobre literatura e história da cultura. Vol. 1, São Paulo: Brasiliense, 1987.

ESQUIROL, Josep M. O respeito ou o olhar atento. Belo Horizonte: Autêntica, 2008.

FERNANDES, Simone Silva. Fontes orais: Perspectivas para o tratamento em centros de documentação e arquivos In ALMEIDA, Juniele R; ROVAI, Marta G.O. Introdução à História Pública. São Paulo: Letra e Voz, 2011.

GINZBURG, Jaime. Crítica em tempos de violência. São Paulo: EDUSP, 2012.

HALBWACHS, Maurice. A memória coletiva. São Paulo: Vértice, 2006.

JELIN, Elizabeth. Los trabajos de la memória. Madrid/Buenos Aires: Siglo XXI, 2001.

NOIRET, Serge. História Pública Digital. Liinc em Revista, Rio de Janeiro, v.11, n.1, maio 2015, p. 28-51.

NORA, Pierre. Entre memória e história: a problemática dos lugares. Projeto História. n.10, dez 1993, p. 7-28.

POLLAK, Michael. Memória, esquecimento e silêncio. Estudos Históricos, Rio de Janeiro, 2 (3), 1989, p .3-15.

RICOEUR, Paul. A memória, a história, o esquecimento. Campinas: Unicamp, 2007. 


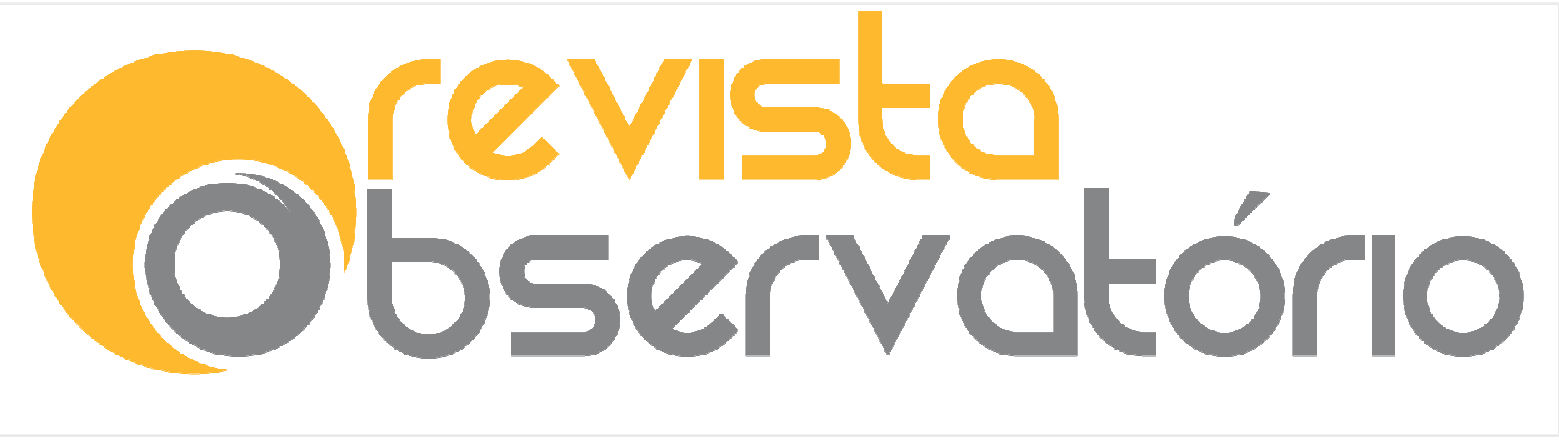

ISSN n² 2447-4266

Vol. 2, n 1, Janeiro-Abril. 2016

DOI: http://dx.doi.org/10.20873/uft.2447-4266.2016v2n1p92

ZAHAVI, Gerald. Ensinando história pública no século XXI In ALMEIDA, Juniele R.; ROVAl, Marta G. O. Introdução à História Pública. São Paulo: Letra e Voz, 2011. 